\title{
Variations in Standard Blood Count and Biochemical Parameters in Dogs with Atopic Dermatitis
}

\author{
Ozana Maria DULMAN ${ }^{1}$, Alina ANTON ${ }^{1}$, Gheorghe SOLCAN ${ }^{1 *}$ \\ ${ }^{1}$ Department of Internal Medicine, University of Agricultural Sciences and Veterinary, Medicine.Faculty \\ of Veterinary Medicine, Mihail Sadoveanu Alley, Nr. 8, Iasi, Romania, 700490 \\ Corresponding author: gsolcan@uaiasi.ro
}

Bulletin UASVM Veterinary Medicine 72(1) / 2015,

Print ISSN 1843-5270; Electronic ISSN 1843-5378

DOI:10.15835/buasvmcn-vm: 10808

\begin{abstract}
Biochemical parameters and complete blood count (CBC) are paraclinical exams that are routinely done in almost any patient. In dogs with dermatological conditions they can help in the differential diagnosis by excluding internal problems that may manifest themselves dermatologicaly.

The aim of this study was to see if atopic dermatitis in dogs can determine any changes in the CBC or in the standard biochemical parameters without clinical manifestations of internal illnesses.

Blood samples (both for CBC and serological analysis) were collected from 15 dogs of different breeds and ages, all diagnosed with atopic dermatitis and no internal organ illness. CBC and biochemical parameters (alanine aminotransferase, aspartat aminotransferase, alkaline phosphatase, gamma glutamyl transferase, cholesterol, glucose, triglycerides, total proteins, blood urea nitrogen, creatinine, amylase, $\mathrm{Ca}, \mathrm{Mg}$ ) were investigated and compared with the reference values.

The most frequent change in biochemical parameters was the low value of Ca ( 6 cases) associated sometimes with low TP ( 4 cases). We also found high values, just above the limit of the reference values, for ALT and ALP (3 cases each). In the CBC we found high values for the granulocytes and white blood cells (4 cases each) or close to the limit of the reference values.

When prescribing treatment for atopic dermatitis we need to consider some parameters, like Ca, ALT and WBC, in order to prevent lowering Ca or aggravating immunosuppression with glucocorticoids or affecting liver functions.
\end{abstract}

Keywords: atopic dermatitis, biochemical parameters, dog

\section{INTRODUCTION}

Canine atopic dermatitis is an allergic condition with primarily dermatological manifestation, but not only. The clinical signs include erythema, alopecia, pruritus, otitits externa, papules, scales, crusts, dry or oily seborrhoea, lichenification, hyperpigmentation and secondary infections (bacterial or fungal). In some patients conjunctivitis, rhinitis or asthma can also be encountered.

The primary lesions are not specific for this condition. Pruritus, for example can be caused by a variety of internal diseases: affected liver functions, uraemia, damage of dermal sensory nerve fibbers, different types of allergies. Alopecia and erythema are common for the ones mentioned above but also for some endocrine or metabolic disorders, chemical or contact local reactions.

A detailed clinical examination along with paraclinical tests chosen based on the initial diagnostic suppositions allow the elimination of many internal illnesses or dermatological problems that may have similar manifestations.

Complete blood count (CBC) and determining standard biochemical parameters are important procedures that help evaluate the patients current health status in order to perform a thorough differential diagnosis. 
CBC offers information regarding a pre-existent anaemia, the white cell formula, stress or inflammatory reactions, possible infections or immune suppression.

The biochemical parameters examined can indicate the status of hepatic functions, kidney filtration capacity, other internal organs or the metabolic profile (Medillec, 2002).

\section{MATERIALS AND METHODS}

15 dogs, of ages between 6 months and 7 years, 6 females and 9 males, were registered with atopic dermatitis in the Internal Medicine Clinic of the Faculty of Veterinary Medicine from Iasi, after a thorough clinical examination and performing other paraclinical tests, like an elimination diet and examining skin scrapings. All the dogs had a good medical status, apart from the dermatological manifestations, no concurrent diseases and a thorough vaccination and deworming schedule followed. All analysis were performed in the Clinical Laboratory.

Three ml of blood were collected from the cephalic vein of the patients in sterile tubes with EDTA as anticoagulant. Five ml of blood were collected in a simple test tube for serum separation (Shyma, 2011).

Complete blood count (CBC) of the samples (white blood cells - WBC, red blood cells - RBC, platelets - PLT, hemoglobin - HGB, hematocrit - HCT, mean corpuscular volume - MCV, mean corpuscular hemoglobin - MCH, mean corpuscular hemoglobin concentration - MCHC, lymphocytes - Lymf, monocytes - Mon, granulocytes - Gra) was performed using an automatic haematology analyzer Vet ABC.

Biochemical estimations of serum alanine aminotransferase - ALT, aspartat aminotransferase - AST, alkaline phosphatase - ALP, gamma glutamyl transferase - GGT, cholesterol - CHO, glucose - GLU, triglycerides - TG, total proteins - TP, blood urea nitrogen - BUN, creatinine - Creat, amylase - Amy, $\mathrm{Ca}, \mathrm{Mg}$ was carried out by spectrophotometry with a Cormay Accent 200 spectrophotometer using Cormay kits.

\section{RESULTS AND DISCUSSION}

From the 15 dogs examined, 6 showed decreased levels for $\mathrm{Ca}$ and in 4 these were correlated with low values in the total protein level (Tab. 1).

These results are not sufficient to imply a metabolic disorder but considering that the main treatment for atopy is based on prednisone, that interferes with the absorption of calcium (Kovalik, 2012), and given that this disease is a dermatological problem that affects the synthesis of vitamin $\mathrm{D}$, the clinical effects appear early in treatment.

Another concerning issue is that 2 bitches had false lactation and another 2 had recently had litters. This represents an additional factor

Tab. 1. Biochemical blood parameters in dogs with atopic dermatitis

\begin{tabular}{|c|c|c|c|c|c|c|c|c|}
\hline \multirow{2}{*}{$\begin{array}{l}\text { Biochemical } \\
\text { parameters }\end{array}$} & \multirow{2}{*}{ Unit } & \multirow{2}{*}{$\begin{array}{l}\text { Reference } \\
\text { values dog }\end{array}$} & \multicolumn{6}{|c|}{ Determined values } \\
\hline & & & 1 & 2 & 3 & 4 & 5 & 6 \\
\hline ALT & ui/l & $8.2-57$ & 76.2 & 45 & 31.1 & 86.3 & 29.7 & 49.1 \\
\hline ALP & ui/l & $10.6-101$ & 20.6 & 137.7 & 45.4 & 17.2 & 39.8 & 22 \\
\hline AST & ui/l & $8.9-49$ & 32.9 & 24.9 & 34.5 & 35.1 & 21.4 & 18.7 \\
\hline GGT & ui/l & $1-9.7$ & 6.2 & 3.9 & 2.1 & 3.1 & 2.5 & 1.7 \\
\hline $\mathrm{CHO}$ & $\mathrm{mg} / \mathrm{dl}$ & $116-254$ & 121.9 & 130.4 & 134 & 204.7 & 213.9 & 172.9 \\
\hline GLU & $\mathrm{mg} / \mathrm{dl}$ & $62-108$ & 71.3 & 87.2 & 82.7 & 76.2 & 76.9 & 72.4 \\
\hline $\mathrm{TG}$ & $\mathrm{g} / \mathrm{l}$ & $20-112$ & 30.9 & 64.7 & 24.5 & 39.3 & 30.1 & 72.3 \\
\hline Creat & $\mathrm{mg} / \mathrm{dl}$ & $0.5-1.6$ & 0.91 & 0.74 & 0.82 & 0.8 & 0.95 & 0.98 \\
\hline BUN & $\mathrm{mg} / \mathrm{dl}$ & $8.8-26$ & 15 & 13.11 & 10.8 & 15 & 14 & 11 \\
\hline PT & $\mathrm{g} / \mathrm{dl}$ & $5.5-7.5$ & 5.02 & 5.1 & 4.9 & 5.13 & 5.92 & 5.53 \\
\hline Amy & ui/l & $270-1462$ & 569.5 & 651.1 & 498.6 & 577.3 & 325.4 & 535.3 \\
\hline $\mathrm{Ca}$ & $\mathrm{mg} / \mathrm{dl}$ & $8.7-11.8$ & 7.15 & 7.56 & 7.74 & 7.3 & 7.62 & 8.03 \\
\hline $\mathrm{Mg}$ & $\mathrm{mg} / \mathrm{dl}$ & $1.7-2.7$ & 1.93 & 1.84 & 1.89 & 2.13 & 2.08 & 1.65 \\
\hline
\end{tabular}


in interpreting these results and considering administration of prednisone. In one case a Sharpei bitch with false lactation manifested a rapid decrease in Ca clinically manifested with tetany, right from the start of the administration of prednisone.

The routine method allows us to determine the total value of the serum calcium: ionic calcium, protein bound and chelated. The physiological variations depend on age, gender and species. It is important that the interpretation of the results is made in view of the protein values (total protein, albumin/globulin ratio). We often see that hypercalcemia is linked to hyperproteinemia and vice versa (Somochochi, 2013).

The total protein level is important when interpreting the $\mathrm{Ca}$ value because unless the albumin/globulin ratio is not well balanced, the ionic fraction of $\mathrm{Ca}$ is affected. Also, when it is associated with an increase in ALT or ALP , before any treatment has been administered, we may consider it useful to prescribe a liver protector among other drugs.

In our study we did not perform additional biochemical analysis (albumins, globulins, total/ ionic $\mathrm{Ca}$ ) mostly because we aimed for a general perspective on the health status of the patient with the purpose of eliminating from the differential diagnostic of internal illnesses that may cause dermatological problems.

Tab.2. CBC values in dogs with atopic dermatitis
Regarding the CBC (Tab. 2), in 7 out of 15 cases, there was an obvious response to the inflammatory process that takes place in the dermis. Lymphopenia and eosinophilia were the main findings associated with neutrophilia and the left deviation of the Arneth index (more than $80 \%$ neutrophils with 1-3 lobes). This indicates a strong corticoid reaction with systemic stress and the start of an infection (increased WBC), most likely a superficial pioderma.

Also, the CBC revealed a slight anemia, macrocytosis, active monocytes, low hemoglobin or hemoglobin concentration. This may indicate that the organism is not ready to fight against a possible infection, even more if this happens to a patient that has a strong corticoid reaction which is supposed to increase the red blood cell number (Kovalik, 2012). If we consider the elevated liver enzymes along the anemia it may be suitable to approach a lower dose of prednisone from the beginning to avoid any hepatic damages.

These findings are useful when formulating the treatment and suggest that besides the corticoid and antihistamine drugs the clinician should also include vitamins, minerals and hepatic protectors. All these help the organism and the immune system to manage the continuous allergen challenge.

There are studies that indicate a favorable effect of vitamin D and calcium supplementation

\begin{tabular}{|c|c|c|c|c|c|c|c|c|c|}
\hline \multirow{2}{*}{ Parameters } & \multirow{2}{*}{ Unit } & \multirow{2}{*}{$\begin{array}{l}\text { Reference } \\
\text { values dog }\end{array}$} & \multicolumn{7}{|c|}{ Determined values } \\
\hline & & & 1 & 2 & 3 & 4 & 5 & 6 & 7 \\
\hline WBC & $\mathrm{x} 10^{3} / \mathrm{mm}^{3}$ & $6-17$ & 20.8 & 18.1 & 18.3 & 17.4 & 18.7 & 21 & 12.6 \\
\hline $\mathrm{RBC}$ & $\mathrm{x} 10^{3} / \mathrm{mm}^{3}$ & $5.4-7.8$ & 5.09 & 5.2 & 7.49 & 6.88 & 5.46 & 6.07 & 7.49 \\
\hline HGB & $\mathrm{g} / \mathrm{dl}$ & $13-19$ & 13 & 11.8 & 15.4 & 15.8 & 12.3 & 15.6 & 15.4 \\
\hline HCT & $\%$ & $37-54$ & 37.2 & 34.3 & 50 & 47.1 & 37 & 48 & 50 \\
\hline PLT & $\mathrm{x} 10^{3} / \mathrm{mm}^{3}$ & $160-430$ & 396 & 421 & 225 & 486 & 508 & 375 & 225 \\
\hline MCV & $\mu \mathrm{m} 3$ & $64-74$ & 69 & 66 & 66.75 & 68 & 68 & 79.07 & 66.75 \\
\hline $\mathrm{MCH}$ & $\mathrm{pg}$ & $22-27$ & 24 & 22.6 & 20.56 & 23 & 22.4 & 25.7 & 20.56 \\
\hline $\mathrm{MCHC}$ & $\mathrm{g} / \mathrm{l}$ & $34-36$ & 34.9 & 34.3 & 30.8 & 33.6 & 33.2 & 32.5 & 30.8 \\
\hline Limf & $\mathrm{x} 10^{3} / \mathrm{mm}^{3}$ & $1.2-3.2$ & 1 & 1.4 & 0.3 & 3.5 & 1.6 & 0.73 & 0.3 \\
\hline $\operatorname{Limf}$ & $\%$ & $12-30$ & 5 & 8.1 & 2.4 & 10.8 & 8.7 & 3.5 & 2.4 \\
\hline Mon & $\mathrm{x} 10^{3} / \mathrm{mm}^{3}$ & $0.3-0.8$ & 0.3 & 0.4 & 0.89 & 0.6 & 0.4 & 2.02 & 0.89 \\
\hline Mon & $\%$ & $3-10$ & 1.7 & 2.4 & 7.1 & 3.5 & 2.4 & 9.6 & 7.1 \\
\hline Gra & $\mathrm{x} 10^{3} / \mathrm{mm}^{3}$ & $1.2-6.8$ & 19.5 & 16.3 & 11.55 & 15 & 16.7 & 20.9 & 11.4 \\
\hline Gra & $\%$ & $62-83$ & 93.3 & 89.5 & 90.5 & 85.7 & 88.9 & 95.7 & 90.5 \\
\hline
\end{tabular}


(Baiz, 2014; Hata, 2008; Somochochi, 2013) when prescribing the treatment for atopic dermatitis. The first has an important role in the immune function of the skin, 1,25-dihydroxyvitamin D $(1,25[\mathrm{OH}] 2 \mathrm{D})$, the active form of $25(\mathrm{OH}) \mathrm{D}$ enhances keratinocyte differentiation and has stimulatory or suppresive effects on keratinocyte growth. It also decreases the inflammatory response in the epidermis. It promotes regulatory $\mathrm{T}$ cells that play an important role in the prevention of atopic dermatitis development by modulating the immune response, it has a beneficial effect on the permeability of the epidermal barrier, it promotes the production of antimicrobial peptides and has the ability to enhance immunity and protect skin from bacterial infections. The sole supplementation with it may improve the absorption and fixation of calcium allowing us to administer other minerals without the risk of competition between ions with similar charge (Baiz, 2014).

\section{CONCLUSION}

1. Biochemical analysis showed decreased values for Ca in 6 out of 15 cases and low TP in 4 dogs with atopic dermatitis.

2. After performing the $\mathrm{CBC}$ we found a strong corticoid reaction and signs of anemia in 7 patients.
Acknowledgements. This paper was published under the frame of European Social Fund, Human Resources Development Operational Programme 2007-2013, project no. POSDRU/159/1.5/ S/132765.

\section{REFERENCES}

1. Baiz N, Dargent-Molina P, Wark JD, Souberbielle JC, Annesi-Maesano I (2014). EDEN Mother - Child Cohort Study Group- Cord serum 25-hydroxyvitamin D and risk of early childhood transient wheezing and atopic dermatitis. J Allergy Clin Immunol January 2014:147-153.

2. Hata T, Kotol P, Jackson M, Nguyen M, Paik A, Udall D, Kanada K, Yamasaki K, Alexandrescu D, Gallo RL (2008). Administration of oral vitamin D induces cathelicidin production in atopic individuals. J Allergy Clin Immunol, October 2008:829-831.

3. Kovalik M, Thoday KL, Evans H, Berry J, van den Broek AHM, Mellanby RJ (2012). Short term prednisolone therapy has minimal impact on calcium metabolism in dogs with atopic dermatitis. The Veterinary Journal 193:439-442.

4. Medillec C (2002). Vede-Mecum des Analyses Veterinaires. MED'COM, Paris.

5. Somochochi Z, Bogaczewicz J, Jeziokowska ASJ, Glinska O, Karczmarevicz E, McCauliffe DP, Wozniacka A (2013). Vitamin D effects in atopic dermatitis. J Am Acad Dermatol 69(2):238-244.

6. Shyma VH, Vijakumar K (2011). Haematobiochemical studies in dogs affected with bacterial dermatitis. J Vet Anim Sci 42:20-22. 